HIPPOLYTE TAINE, La storia, il suo presente, il suo futuro

\title{
Andrea Schellino
}

\section{OpenEdition}

\section{Journals}

\section{Edizione digitale}

URL: http://journals.openedition.org/studifrancesi/15694

DOI: 10.4000/studifrancesi. 15694

ISSN: 2427-5856

\section{Editore}

Rosenberg \& Sellier

\section{Edizione cartacea}

Data di pubblicazione: 1 décembre 2018

Paginazione: 521

ISSN: 0039-2944

\section{Notizia bibliografica digitale}

Andrea Schellino, «HIPPOLYTE TAINE, La storia, il suo presente, il suo futuro», Studi Francesi [Online], 186 (LXII | III) | 2018, online dal 01 janvier 2019, consultato il 06 janvier 2021. URL: http://

journals.openedition.org/studifrancesi/15694 ; DOI: https://doi.org/10.4000/studifrancesi. 15694

Questo documento è stato generato automaticamente il 6 janvier 2021.

\section{(c) $(1) \odot$}

Studi Francesi è distribuita con Licenza Creative Commons Attribuzione - Non commerciale - Non opere derivate 4.0 Internazionale. 


\title{
HIPPOLYTE TAINE, La storia, il suo presente, il suo futuro
}

\author{
Andrea Schellino
}

\section{NOTIZIA}

HIPPOLYTE TAINE, La storia, il suo presente, il suo futuro, introduzione e note di Paolo

Tortonese, traduzione di Laura Tortonese, Pisa, Pacini, 2017, coll. «I libri

dell'Associazione Sigismondo Malatesta. I minibook», 126 pp.

1 Paolo Tortonese presenta, nella versione di Laura Tortonese, la traduzione italiana de L'Histoire, son présent, son avenir di Hippolyte Taine. Questo saggio, pubblicato il primo dicembre 1863 nella «Revue germanique et française», fu utilizzato da Taine lo stesso anno come Introduction all'Histoire de la littérature anglaise. Nella sua ampia introduzione, Paolo Tortonese fornisce una sintesi efficace dei metodi e della filosofia della storia del pensatore francese: più «negativista» che «positivista» (p.9), lettore eclettico di Spinoza, di Dugald Stewart, di Esquirol e di Stendhal, Taine fonda una psicologia come «attività ermeneutica», che vuole rivelare, di un uomo del passato, «qual è l'ordine, quali sono il genere e la forza abituale delle sue idee, in che modo pensa e decide» (p. 23). Paolo Tortonese invita a non confondere il parallelismo tra causalità fisiche $\mathrm{e}$ causalità morali che Taine stabilisce con una «dichiarazione determinista» o «riduzionista» (p.25), come fu fatto all'epoca e come ancor oggi avviene. Taine attribuisce piuttosto allo storico il compito di cogliere quel sistema coerente che è la realtà umana, di cercare le «idee rappresentative», di «intravvedere il nucleo originario, e descrivere tutte le diverse modificazioni che ha subito» (p. 34).

2 In appendice del volume, si può trovare la traduzione in italiano della Préface di Taine alla seconda edizione degli Essais de critique et d'histoire (1866). 